\title{
Editorial
}

\section{Antibiotic prophylaxis of infective endocarditis for dental procédures: the British act of contrition?}

"For those who believe no proof is necessary. For those who don't believe, no proof is possible". (Stuart Chase, 20th century American philosopher and economist).

There has been substantial medical literature about this topic in the past 2 years, with no less than 30 publications referenced in PubMed Central from 2016! Almost all of them now agree the need, if not the justification, of antibiotic prophylaxis (AP) in patients at high risk of infective endocarditis (IE) before invasive dental procedures, while admitting that the benefit provided in term of reducing the number of IE cases is difficult to quantify.

In a previous editorial a little over 3 years ago, I drew your attention to the fact that the lack of evidence for the effectiveness of such a procedure is not the evidence that it is not effective [1]. British experts of the NICE (National Institute for health and Clinical Excellence; equivalent of the French national High Authority for Health) who established guidelines in 2008 (updated in 2015) recommending the cessation of all AP in this context [2], seem to have realized this now.

Why this sudden change of direction? It is most likely due to the study of Dayer et al., in which the authors (experts of the NICE), showed a small but significant increase of the incidence of IE since the cessation of AP in United Kingdom. This increase was demonstrated not only in patients at high risk of IE but also in those with lower risk [3]. Without questioning the NICE guidelines, this study introduced an element of doubt to the previously held beliefs. Consequently, NICE amended its position stipulating that in individual cases where the risk of IE posed to the patient is perceived sufficiently high, or when the patient themselves express a preference for it, AP may be appropriate [4]. The implementation of this amendment may be difficult because the recognition of a "sufficiently" high level of IE risk is left to the practitioner; however, this underlined a major evolution in the NICE'S attitude towards this topic.

A few weeks later, this team of British experts of the NICE conducted a study about the economic relevance of AP for the EI prevention in the patients at risk [5]. Authors concluded that AP was less costly and more relevant than the absence of such
AP in these patients. In 2017, the same team of authors published in Heart a systematic review and meta-analysis about the effects of AP on postoperative bacteremia induced by invasive oral procedures in patients at high risk of IE [6]. From the 36 selected studies, authors showed that decreased bacteremia was significantly correlated with the presence of AP but this did not necessarily imply a decrease in the incidence of IE. Methodological approaches not often similar could explain this discrepancy.

However, it is important to notice that 2 of these authors, Mark Dayer and Martin Thornhill, in a recent review have proposed several very interesting meanings [7]. "It remains unclear as to whether AP is effective" (how good it is). There are no adequately powered randomised controlled trials to help inform décision making in this field, and due to the rarity of the disease, there may never be. What is required is a synthesis of the evidence that does exist, followed by an honest balancing of the risks and benefits. We believe that when the evidence is taken as a whole it is impossible to exclude the possibility that AP does have an impact, albeit small". Reluctances of the past about antibiotic resistance, fatal anaphylaxis and the additional cost of AP seem no longer relevant because probably very minimal. "Therefore, the concept of marginal gain so popular in many fields, particularly in sports, could be applied to reduce the impact of IE and improve the results of $A P^{\prime \prime}$.

They concluded: "We believe, when all of the evidence is considered that AP is just one such marginal gain in the ongoing battle against that the benefit outweigh the risks particularly for the use of AP in those at high-risk of possibly for those at moderate-risk although we accept that définitive evidence is lacking".

It is great to see that yesterday's critics of AP are its defenders today! Will the British change their minds again (the NICE guidelines, even amended, are still in force)? It is highly possible. Nevertheless, we should salute this British team of authors that has managed to challenge previous ideas.

Medicine is not an exact science, once again it's verified.

Philippe Lesclous 


\section{References}

1. Lesclous P. L'antibioprophylaxie de l'endocardite infectieuse en pratique bucco-dentaire: Recherche Vérité désespérément! Med Buc Chir Buc 2015; 21: 3-4.

2. National Institute for health and Care Excellence. Guideline 064Prophylaxis against infective endocarditis. NICE 2015. https:// www.nice.org.uk/guidance/cg64.

3. Dayer MJ, Jones S, Prendergast B, Baddour LM, Lockhart PB, Thornhill MH. Incidence of infective endocarditis in England, 200013: a secular trend, interrupted time-series analysis. Lancet 2015. DOI: 10.1016/S0140-673(14)62007-9.
4. Thornhill MH, Dayer MJ, Lockhart PB, McGurk M, Shanson D, Prendergast $B$, Chambers JB. A change in the NICE guidelines on antibiotic prophylaxis. Br Dent J 2016; 221: 112-114.

5. Franklin M, Wailoo A, Dayer MJ, Jones S, Prendergast B, Baddour LM, Lockhart PB, Thornhill MH. The cost-effectiveness of antibiotic prophylaxis for patients at risk of infective endocarditis. Circulation 2016; 134: 1568-1578.

6. Cahill TJ, Harrison JL, Jewell P, Onakpoya I, Chambers JB, Dayer M, Lockhart P, Roberts N, Shanson D, Thornhill M, Heneghan CJ, Prendergast BD. Antibiotic prophylaxis for infective endocarditis: a systematic review and meta-analysis. Heart 2017; 103: 937-944.

7. Dayer M, Tornhill M. Is antibiotic prophylaxis to prevent infective endocarditis worthwhile? J Infect Chemther 2018; 24: 18-24. 